\title{
Los usos políticos de la memoria y la identidad
}

Alejandro Isla P. ${ }^{1}$

\section{RESUMEN}

Este artículo trata de relacionar las formas del recordar, con el campo de la política a través de la emergencia de identidades étnicas. La memoria, como narración del pasado -fragmentos narrativos-, es un campo de abundantes disputas, cuando se dirimen identidades nacionales o étnicas. Se demuestra por medio del caso tratado que las conmemoraciones resultan escenarios propicios para que las biografías particulares y la acción de rememorar de los sujetos se inscriban en una memoria oficial o colectiva de un conjunto de personas. Esas celebraciones son cronotópicas, pues además de rememorar ensalzando aspectos significativos del pasado para los participantes, intentan determinar el futuro en el presente de las mismas, esculpiendo el devenir en las expresiones simbólicas de los rituales conmemorativos. Pero además, la memoria está relacionada a un territorio y a sus reclamos.

Palabras claves: memoria e identidades - mito e historia en las comunidades andinas - hegemonía cultural bajo los Estados nacionales.

\begin{abstract}
This article aims to establish the relationship between different ways of remembering and the politic arena, through the study of the emergence of ethnic identities. As a narration of the past, as narrative fragments, memory is a field of many struggles when national or ethnic identities are involved. The case study presented here shows how commemorations are propitious scenarios for inscribing individual biographies and personal memories into official ones, or in those collectively constructed by a group. Such memorials are chrono-topical because, along with enabling memory through the celebration of significant aspects of the participants past, they attempt to shape their future in the present, directing the flow of events by means of symbolic expressions in commemorative rituals. Memory, moreover, relates to a territory and its underlying claims.
\end{abstract}

Key words: memory and identities - myth and history in an Andean community - cultural hegemony under the nation State.

Recibido: febrero 2004. Manuscrito revisado aceptado: mayo 2004

CONICET, FLACSO, Antropología. Calle Ayacucho 551 (1026), Buenos Aires, ARGENTINA. Email: aleisla@mail.retina.ar.

\section{Introducción}

Propongo vincular en este artículo la noción de memoria en relación a la de identidad para iluminar sus usos políticos en la construcción del presente. Tomaré el caso emblemático de la Comunidad de Amaicha del Valle, en los Valles Calchaquíes (provincia de Tucumán, Argentina), para ilustrar este juego de relaciones y representaciones (Figura 1). Pero antes de entrar en el caso debo explicar la articulación que entiendo existe entre las nociones de "identidad", "memoria" e "historia".

Es abundante y parte de un debate académico reciente la bibliografía que discute las nociones de "memoria" e "historia". Nociones unidas de alguna forma por la temporalidad, por la representación individual o colectiva del devenir. Sabemos que esta "temporalidad" no es inocua a la cultura, por más materialidad física que encontremos en el ciclo vital, en los ciclos agrarios, en los períodos lunares, en las estaciones. Desde los estudios clásicos de Hubert y Mauss de 1909, o de Edmund Leach de 1966, aprendimos que la percepción del tiempo es diferente entre variadas culturas. Además esta percepción, y la conceptualización que muchas veces acompaña lo sensible, puede transformarse dentro de una larga tradición cultural como la de Occidente, en la cual durante la Antigüedad Clásica la percepción del tiempo estaba completamente asociada a nociones "circulares" impresas en los mitos, como demostró Leach. Este antropólogo, en sus indagaciones sobre el mito, comparó las nociones de temporalidad en la Grecia presocrática con aquellas que se elaboraron en los tiempos de Platón (Detienne 1994 [1967]) y, a su vez, con la conceptualización del tiempo entre los kachin, donde realizó sus estudios de campo pormenorizados.

La conclusión es que la idea del tiempo es una construcción cultural, cuestión que es una certeza para quienes hemos trabajado en los Andes Cen- 


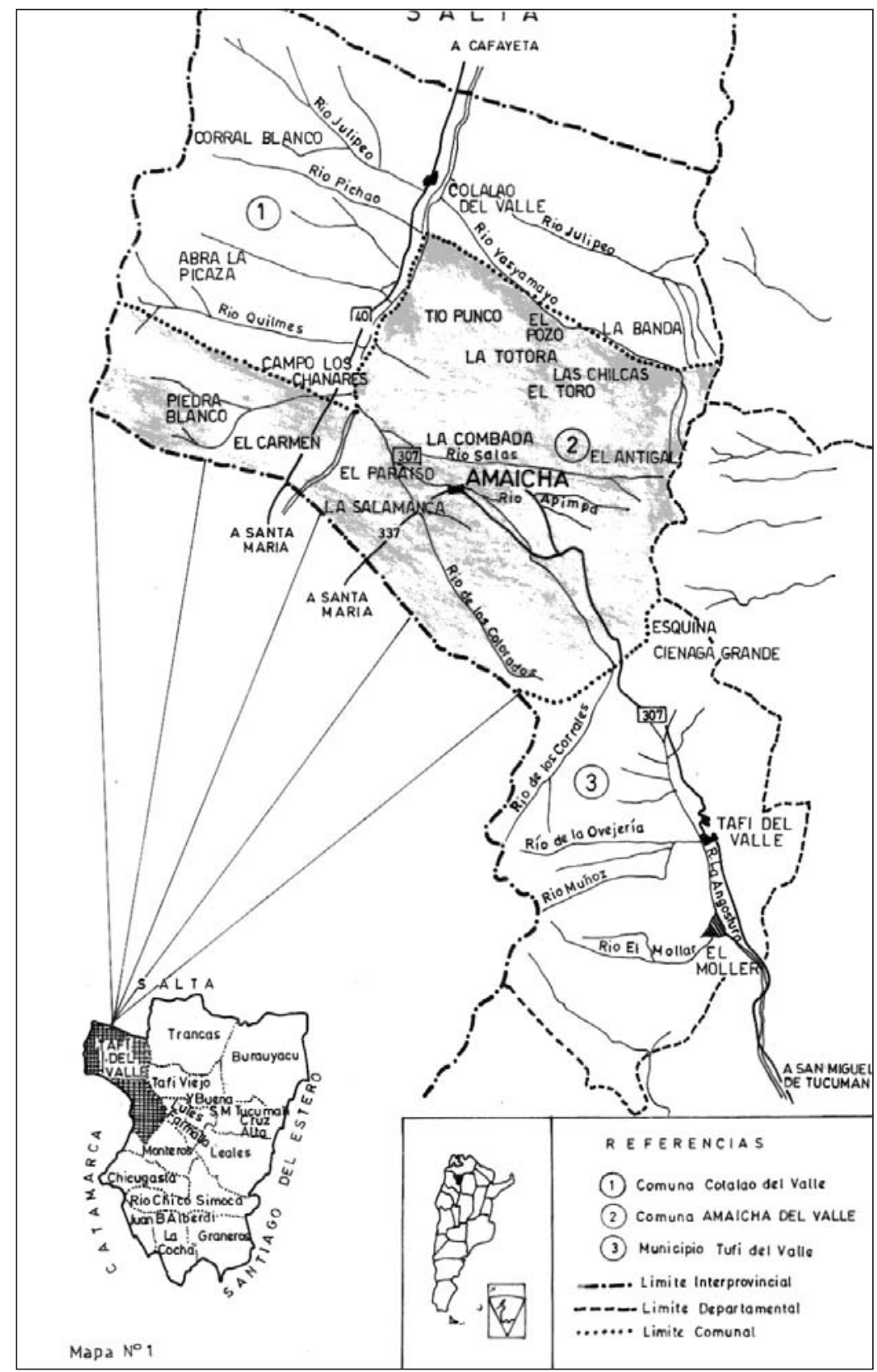

Figura 1. Ubicación del territorio que habita la Comunidad de Amaicha del Valle, en los Valles Calchaquíes (provincia de Tucumán, Argentina).

trales. ${ }^{2}$ Allí la percepción del tiempo, con los acontecimientos anuales fortuitos, se halla anclada en los rituales asociados a los sistemas de cargo (Rivière 1995) en los rituales cíclicos agrarios con

\footnotetext{
2 El autor trabajó en una comunidad aymara en el Cantón Tiwanaku, al sur del Titicaca.
}

sus respectivos rituales, marcados, por ejemplo, con la rotación de las aynukas ${ }^{3}$ (Isla 1984).

\footnotetext{
3 Tierras de sembradío, esparcidas en el territorio de la comunidad, donde cada familia tiene una o más pequeñas parcelas. Los ciclos de actividad / barbecho de cada aynuqa son conocidos y respetados por todos los miembros de cada comunidad o ayllu.
} 
La rotación de cargos, como de aynuqas, están en los Andes Centrales entre los más importantes lugares o instituciones que "fijan" el transcurrir en la memoria de los actores. Por ello deben ser pensados como sistemas o mojones, que enmarcan la memoria del pasado, que la contextualizan, operando en el sentido de lo que Bajtín (2003) llamó crono topos. ${ }^{4} \mathrm{O}$ sea, formas de atar o relacionar los acontecimientos pasados y lo que llamamos "el por-venir", al presente cotidiano. Los crono topos no cumplen sólo una función de "ayuda memoria", sino que encierran en una síntesis espacio-temporal (física, social y simbólica) aspectos relevantes para la comunidad del pasado (conformando o ayudando a conformar una "memoria colectiva", o una "historia oficial") que permiten inteligir el devenir y actuar en consecuencia sobre un presente concreto, específico.

Pero en los casos estudiados en el Noroeste Argentino los sistemas de rotación que funcionan en los Andes Centrales, en los diferentes niveles de la cultura, se han extinguido sin dejar evidencias que permitan aseverar que alguna vez existieron. Sin embargo, en algunos sitios de esa amplia región, sus habitantes a fines de los ' 80 , y más masivamente a principios de los ' 90 , comenzaron a reconocerse en alguna de las variadas culturas indígenas que allí habitaron. Este fue un verdadero despertar de identidades que habían permanecido negadas, discriminadas, siempre subalternizadas, y muchas veces olvidadas, como restos de un pasado remoto, que ya no tiene que ver con el paisaje de hoy.

De allí que los pobladores que tímidamente iniciaron el proceso de asumir esas identidades denostadas hasta la actualidad deben reconstruir o más aún inventar ${ }^{5}$ una memoria con el objeto de incidir políticamente sobre el presente, especialmente en las cuestiones del reclamo y la protección de los derechos sobre la tierra, que en el caso de Amaicha se fundamentan e inscriben sobre un documento de principios del siglo XVIII.

4 Especialmente en su estudio "Tiempo y espacio en Goethe" (Bajtín 2003: 235).

5 Usaré "reconstruir" a lo largo del texto no considerando "la invención de memoria" o de recuerdos como procesos opuestos. Ambos son procedimientos utilizados indistintamente, y a menudo de forma inconsciente por los actores. Son parte del trabajo de reconstruir mítica y/o ideológicamente el pasado, en forma de recitado colectivo. Ricoeur hablaba de un verdadero travail de souvenir (1991).
Esa reconstrucción nomotética puede realizarse mediante el destacar determinados hitos del pasado, emblematizar documentos históricos (monumentos o folios escritos) enarbolando una ideafuerza organizacional, ${ }^{6}$ sobre la cual se teje el entramado de la historia reconstruida.

Además, como política de la memoria, se construye una retórica épica de la lucha por el territorio en contra del Estado colonial y nacional, que liga los reclamos del presente (pensando, desde los actores, con espesor de siglo) con la evocación de las "rebeliones" o "guerras calchaquíes" del XVII. Estas son relatadas por gran parte de los calchaquíes hoy vivientes como una narración mítica de sus orígenes, como de los buenos tiempos antiguos, cuando los "antepasados", que hasta hoy los visitan saliendo de sus antigales, ${ }^{7}$ vivían en un reino de esplendor.

Esta retórica, en el caso de los calchaquíes amaicheños y quilmeños, se basa en un conocimiento colectivo y extendido entre los comuneros del contenido de la Cédula Real, como documento histórico y protocolizado frente al Estado nacional. Para ellos argumenta el derecho legítimo al territorio de más de 90.000 has, que hasta fines del siglo XX reclamaron en posesión comunal. Un tipo de posesión que recién el Estado-nación reconoció ambiguamente en 1994, en el texto de la nueva Constitución Nacional.

Podría decirse que la historia de la Cédula Real (documento que consigna la cesión de tierras, en el cual el Rey de España en 1716 cedió territorio "en comunidad" a un grupo de "naturales") se constituyó en un icono para la historia de los Valles Calchaquíes. ${ }^{8}$ Algunos comuneros afirman hoy, que conservaron celosamente protegidos, dos legados a lo largo de tres siglos: "la Cédula y el árbol genealógico", el primero un documento con existencia real, el segundo una invención colectiva.

En el "árbol", según los comuneros, se encuentra el listado de los amaicheños "originarios"; o sea, miembros de aquellas familias que, según ellos, formaron parte del núcleo de pobladores que fueron reconocidos como tales a principios del siglo XVIII.

6 Me refiero a la idea-fuerza comunidad, extendida y convincente para un conjunto heterogéneo de personas.

7 Denominación popular en el N.O.A. para "sitios arqueológicos".

8 Reproducida en varias fuentes secundarias, entre ellas Isla (2002). Copia en Archivo Histórico de Tucumán. 
Siguiendo su versión sobre el "árbol genealógico", afirman que es un documento secreto guardado bajo rigurosa custodia. Sin embargo, el 7 de junio de $1947^{9}$ debieron presentarlo frente a tribunales provinciales para la determinación de herederos y sucesores (La Gaceta 28/07/74). Según mi propia interpretación de los hechos, ese listado se confeccionó en 1947 por el requerimiento del Catastro de Tierras de la provincia de Tucumán consignando los pobladores asentados a esa fecha. En las versiones comuneras subsiguientes, a esas familias se les llamó "originarios" y se inventó, a su vez, sus raíces remotas.

El conocimiento del contenido e importancia de la Cédula ha sido transmitido de generación en generación, promoviendo todo tipo de reclamos en el período republicano. A pesar de una temprana inscripción en el Cabildo de Buenos Aires (1853), los intentos de desconocer este derecho y apoderarse de las tierras fueron continuos hasta el presente. La "protocolización"10 del documento no se consigue hasta 1892 . Recién en esa fecha, a raíz de un pleito entre un hacendado, vecino de la ciudad de Cafayate (en la provincia de Salta), y los comuneros. Estos logran, después de un largo litigio, que su posesión fuera de alguna manera inscrita en la provincia. Esto ayudado también por el temor de las autoridades de Tucumán de que esas tierras quedaran incluidas definitivamente en la provincia de Salta (testimonios orales y Lizondo 1987 Ms).

Para los comuneros actuales la Cédula Real es un documento fundador de su historia. Durante décadas fue escondido por los mismos aduciéndose su pérdida, frente al temor de que les fuera sustraído. Muchos comuneros lo memorizaron en forma textual, como una precaución frente al extravío, al robo, a la manipulación. El cacique Cano, del paraje la Merced que gobernó la comunidad a principios del siglo XX, decía Alfonso Carriso "...él es ahora el Guaitina ${ }^{11}$ de los amaicheños....". ${ }^{12}$

9 Encabezados por su cacique Agapito Mamani.

10 Vale decir, que se registre foliado en el archivo catastral de provincia.

11 Según Carriso, al padre Cabrera le asignaban la significación de “...principal, grande, jefe, cacique principal...en lengua Calchaquí o cacano..." (Carriso 1937: 244).

12 Continuando con su comentario sobre el jefe calchaquí Cano “...y lo será por muchos años remplazando así con toda eficacia a Don Diego Uti o Diego Utiguaitina que acompañó a su parcialidad en el éxodo de noviembre de 1665 , cuando fueron extrañados a orillas del río Salí, frente a Famaillá por su encomendero, el alférez don Francisco de Abreu y Figueroa" (Carriso 1937: 35).
Ese cacique Cano dio pruebas de su responsabilidad como jefe calchaquí, ya que le recitó "de memoria" al autor del Cancionero Popular el documento completo de la Cédula Real (1937, Tomo I, 36).

Es el único caso conocido de "comunidad" en Argentina que mantiene la Cédula Real en la memoria $^{13}$ y en las prácticas del conjunto. Los comuneros guardan además en su memoria un sinnúmero de episodios relacionados a la tierra y a su defensa por "sus legítimos dueños", construyendo una épica de la lucha y de los sacrificios que debieron realizar a lo largo de los siglos. Este discurso con variaciones y diferentes tonalidades se puede encontrar en los últimos rincones de la comunidad de Amaicha, como también en su aledaña Quilmes.

Esta memoria colectiva o social, construida y recreada como todas las memorias, enfatiza hechos aislados del pasado, otorgándoles el carácter de símbolos o blasones históricos, en las prácticas del presente amaicheño cotidiano. $\mathrm{O}$ sea, por un lado son invocados como una forma política de identidad ya que le da raíces a un "nosotros" que fue masacrado y en gran parte desterrado durante el siglo XVII. Pero por otro, el contenido y la estructura mítica de los relatos, que aluden a un origen primigenio en ese territorio, da fuerza y substancia a las prácticas que se encaminaron a lo largo de los siglos a la recuperación del mismo. El nuevo surgimiento de identidades indígenas, inventando grandes trazos de su tradición e historia, se produjo a partir de la última etapa democrática (desde 1983) vinculado a la defensa de los derechos, en particular a los reclamos por la tierra-territorio.

13 Puede haber otros casos como el de las tierras comunales de Tilcara que fueron entregadas a los indígenas por Felipe III el 10 de junio de 1606: “...en Nombre de Don Felipe Viltipoco cassique prinsípal del pueblo de Tílcara... Dígo que a los sussodichos de tiempo Ynmemorial aesta parte Antenido Y possydo epossen al presente por tíerras propías Y por suYas qie estan desde La quebrada de Yucara hasta el Río de Omaguaca $Y$ desde allí el Río arriva hasta el asiento de Tumí de Vna banda y de otra Y otras tíerras en La quebrada de purmamarca hasta las tíerras de Yucayra, Y chelísto, Y maymala y tílcara y tumí..." (Sánchez 1996: 52-81), cuyos vestigios como "tierras de comunidad" se desvanecen en el tiempo, por los años '30 del siglo XIX. Hoy, los descendientes de aquellos no guardan memoria de esas tierras como comunidad, y nunca durante la etapa republicana se las reclamó como tal. 
De esta forma, estoy entendiendo la necesidad de articular los conceptos de mito e historia, con memoria. Nora sostiene en su monumental obra que nociones tales como "...memoria e historia, están lejos de ser sinónimos...”. Para este historiador que ha teorizado esas relaciones a la luz de los símbolos paradigmáticos del Estado-nación francés, la memoria

“...permanece en una continua evolución, abierta a la dialéctica del recuerdo y del olvido, inconsciente a sus sucesivas deformaciones, vulnerable a la manipulación y apropiación, susceptible de permanecer largos períodos dormida y periódicamente ser revivida... Es un fenómeno perpetuamente actualizado, un lazo que nos liga al eterno presente; historia es una representación del pasado. La memoria, en tanto y en cuanto es afectiva y mágica, solamente acomoda aquellos hechos que le convienen a su medida..." (Nora 1997 [1984]: 24-25).

Una de sus principales conclusiones que se desprenden de sus elaboraciones es que la memoria "se encuentra vinculada a sitios, mientras la historia se encuentra vinculada a acontecimientos..." (Nora 1997 [1984]: 41).

Sin embargo, desde mi perspectiva teórica uno de los procedimientos o funciones implícitas en las narrativas míticas es el de relacionar sitios con eventos, y las representaciones de los mismos se encuentran encarnadas en la vida cotidiana de la gente (Isla 1998).

Desde la perspectiva de los actores que han asumido y reconstruido, en una misma operación, un discurso a partir de acontecimientos pasados, hilvanados en una retórica mítica, pues da cuenta de un origen glorioso y sagrado, tanto la memoria como la historia se hallan ancladas en "lugares" de un territorio específico. Para los pobladores es imposible así el separar "acontecimiento" de "lugar" o "sitio".

La memoria produce un transitar impredecible entre "sitios" que se tornan "acontecimientos", y éstos, a su vez, en "lugares". O como aclaraba Rousso, también en torno a la concepción de Nora,

"los lugares inteligibles, donde se forman las representaciones colectivas del pasado, ... surgen a través de un prisma de acontecimientos singulares y remarcables, vividos como tales por los con- temporáneos... que son los puntos del recuerdo, los hitos fundadores de la representación, y de la reapropiación y la reconstrucción permanente del pasado por los actores sociales" (1991: 249).

Estos "lugares" no se deben pensar sólo como monumentos, o sitios sagrados (como los picos de las montañas en las culturas andinas) o los antigales, sino también como instituciones o rituales celebratorios, que en los Valles Calchaquíes ocupan una actividad anual importante; por ejemplo, las festividades dedicadas a la Pachamama.

Entonces, es allí donde la subjetividad, a través de la experiencia individual, se nutre de una memoria colectiva transmitida, y se ancla en relaciones sociales concretas que le dan (a esa experiencia) marco y sustento. Pero esta memoria colectiva, o "las representaciones colectivas del pasado" expresadas en los discursos de los actores, nunca son homogéneas y tampoco estables. Es un fermento que se encuentra en permanente elaboración, como más adelante fundamentaré.

Así la memoria vallista, como la historia relatada, están fuertemente relacionadas a un territorio. Sus reclamos no apuntan sólo a una demanda de tierra, para la producción agropecuaria, sino a un "sitio", parafraseando y en el sentido de Nora, que ellos entienden y sienten como sagrado. Ya que allí está su origen, como grupo social y etnia. ${ }^{14} \mathrm{El}$ que además está poblado de los vestigios de "sus" ancestros; o de quienes ellos reconocen como "sus" ancestros. Para ellos, lo que nosotros llamaríamos sin más "ruinas arqueológicas" no son otra cosa que signos vivientes, a veces amenazantes, de "su" pasado. Pero, a ese territorio, y a su reivindicación étnica, coadyuva la memoria reconstruida de las guerras calchaquíes del siglo XVII y de otros eventos históricos y aún lo que los académicos llamaríamos arqueológicos.

Subrayo el posesivo "su", puesto que aunque se demostrara que esos valles vaciados por las masacres y destierros en las postrimerías del siglo XVII, fueran repoblados por otros grupos andinos durante los siguientes siglos, los que allí llegaron recrearon una historia avalados por una

\footnotetext{
14 La base de ese poder es el control del territorio como germen de nacionalidad, y entonces, incluso de Estado (Carter y Albó 1988).
} 
serie de documentos y restos de arquitecturas devastadas para nosotros, pero que para "ellos" se encuentran pobladas de ancestros, duendes y espíritus deambuladores, sobre los que circulan profusas narraciones que los corporizan y reviven.

Así algunos mitos que parecen dormidos en el flujo de la historia, de repente relumbran con fuerza en la conciencia de los pobladores. O como diría Benjamin (1989): "articular históricamente lo pasado no significa conocerlo tal y como verdaderamente ha sido. Significa adueñarse de un recuerdo tal y como relumbra en el instante de un peligro...". Y ese peligro para los vallistos, tanto amaicheños, como quilmeños, ha sido la permanente amenaza sobre su tierra / territorio, sobre su identidad, y entonces sobre su tradición.

La transmisión de esas narrativas se realiza en el transcurso de la vida cotidiana, en la intimidad del hogar o en los trabajos diarios, en general a contrapelo de la historia que se imparte en la escuela, émulo del Estado-nación en la localidad. Son relatadas de padres a hijos en un sentido pasivo, como una tradición, o cuentos transmitidos por abuelos a nietos. Pero esa pasividad, propia del género del relato, se va encarnando en las prácticas, en las memorias, en los imaginarios.

Los comuneros guardan de esta forma una viva y orgullosa memoria sobre el título de merced real. Ese documento es un emblema político constituyente de su identidad como calchaquíes, que legitima el reclamo de sus tierras. Estos reclamos debieron extremarse en el período republicano, diversificando sus expresiones e instrumentos, utilizando instancias políticas, jurídicas, rebeliones, ocupaciones, haciéndose duchos en el arte de litigar (Isla 2002).

Los amaicheños, como andinos piensan que "la tierra es la base donde todos estamos parados". La "tierra" es mucho más -para ellos- que un medio de producción. Es la fuente de la vida, por lo tanto, de su sociedad. De allí que celebran la Pachamama, en medio de los ritos y creencias católicas. Reconociendo "sus caprichos" deben encomendarles sus cultivos y ganados, sabiendo que a veces la Pacha se los "arrebata" sin razón aparente. Por ello, se requieren ingentes y constantes esfuerzos, que implican todos los planos y facetas de la vida cotidiana. Desde las celebraciones y promesas religiosas, hasta las contiendas y prácticas políticas más sutiles y laberínticas dentro del Estado, con el objeto de cuidar su patrimonio.

La tierra así, es claro núcleo de litigios entre las facciones, que en muchas oportunidades de la historia de Amaicha hace resurgir la identidad comunera. Al adquirir fuerza de colectividad o comunidad, la tierra se convierte en territorio. Las disputas pueden adquirir ribetes dramáticos. Más allá de la lenta e inexorable penetración del mercado, ayudada por otra parte por los propios comuneros, el imaginario se asienta en entender y sentir la tierra como territorio o terruño. Es la explicación reiterada para el retorno de los emigrados, cuando han cumplido su ciclo laboral en lugares distantes de los Valles: vuelven a morir en su tierra.

La memoria histórica o memoria colectiva de los comuneros, construida alrededor del documento la Cédula Real y los hitos históricos recordados sobre las luchas por su tierra, implican un esfuerzo o un trabajo de reflexión histórica por parte de los actores. Esta reflexión siempre es

“...un proceso de interpretación de evidencias del pasado, que conlleva inmediatos referentes históricos a través del uso de imágenes y metáforas; ambas, la narrativa y el ritual, ligando el pasado con la contemporaneidad a que hacen referencia..." (Rappaport 1987: 44/45).

Pero agregaría que además de la necesaria mitificación del pasado, sobre lo que vengo insistiendo, esas "imágenes y metáforas, narrativas y rituales", en una sociedad subordinada por más de cuatro siglos, deben necesariamente llevar impresos rastros de las formas de dominación y las hegemonías que han sufrido y que describo pormenorizadamente en otro trabajo (Isla 2002).

La Cédula ${ }^{15}$ opera como elemento central del mito fundacional, cohesiona al grupo de comuneros por el reclamo de la tierra, y los legitima frente al Estado republicano. Pero el discurso de la Cédula que engloba y define a la sociedad amaicheña y quilmeña como comunera, según los propios actores, está contextuado por las prácticas de los

15 De la que se conserva el texto en los tribunales de San Miguel de Tucumán y que reproduje completamente en una obra anterior (ver Isla 2002). 
mismos en sus reclamos jurídico-políticos, como una parte trascendente de sus distintos rituales de identidad. Narrativa y ritual se transforman y refuerzan recíprocamente en las distintas coyunturas históricas.

Más aún, ese "título", como la mayoría de comuneros denomina, constituye el punto central de referencia para la construcción de la historia; o sea, para rehacer el pasado. Muchos de los líderes calchaquíes actuales sostienen que la "comunidad" nace con la Cédula Real. Siguiendo esta argumentación he recogido narraciones que sitúan las "grandes rebeliones" del siglo XVII como luchas posteriores a la entrega del "título" (1716), aduciendo las causas de aquellas a las gestas heroicas y a los sacrificios de la resistencia que debieron realizar los antepasados, con la finalidad de impedir que les quitaran el documento y en consecuencia su territorio.

Pero la forma de pensar y reclamar el territorio se realiza bajo la forma explícita de "comunidad", ${ }^{16}$ más allá de la interesante polisemia del término entre los mismos vallistos. Esta no es sólo una forma sociológica de pensar la organización de la gente rural en los Valles, sino que constituye para los actores una identidad cultural y étnica ${ }^{17}$ al referenciarse al sí mismo como "ser comunero" frente a ser "foráneo". "Comunero" actualmente en los Valles tiene una automática traducción como "calchaquí".

De allí que la memoria de un pasado reconstruido esté estrechamente vinculada a la construcción de identidad, que se expresa en el posicionamiento cotidiano de los actores. La identidad se materializa en las narrativas sobre el pasado (Lambek y Antze 1996: XVIII) que los miembros de una comunidad realizan en la interlocución entre "ellos" y frente a los "otros". El "nosotros" recons-

16 Que tiene implicancias organizativas: la mantención de un gobierno propio (paralelo o superpuesto al de la comuna rural, una institución propia de la provincia de Tucumán, vale decir estatal), un mecanismo particular de acceso y distribución de la tierra, y una de vinculación simbólicoafectiva con el territorio.

17 Toda "identidad" tiene la potencialidad de desplegar componentes políticos explícitos; éste es el caso cuando la identidad está ligada a lo étnico, y a su vez la etnia constituye un sujeto socialmente explotado, culturalmente subalternizado y excluido. Pues exige siempre una autoidentificación grupal frente a un "otro" dominante. truido en el imaginario del pasado puede dentro del discurso de la tradición "calchaquî" ofrecer fuertes contrastes, según la narrativa. Por ejemplo, "héroes" frente al español en las rebeliones, o "víctimas" de sucesivos despojos de tierras, derechos y costumbres. Como es el caso de la lengua que se extinguió a principios del siglo XVIII casi sin dejar vestigios.

Hace más de tres siglos que el kakano -la lengua de los pobladores originarios de los Valles- se desvaneció, sólo dejando rastros efímeros en la toponimia. Esto constituye un motivo de preocupación para los dirigentes de los Valles que se reconocen en la identidad indígena. Uno de los cuales reflexivamente explicaba ese drama mediante la metáfora: "conservamos el cuerpo, pero perdimos el alma" ${ }^{18}$ indicando la victoria sobre la mantención del territorio como "cuerpo", pero la derrota en la conservación del "alma", o sea, la lengua.

Pero Amaicha además de ser Comunidad Indígena, ungida como tal por el Estado nacional, presenta otra cara institucional: es la "Comuna de Amaicha del Valle", constituyendo una de las 92 comunas rurales que la provincia de Tucumán tiene registradas y reconocidas por sus leyes y constitución. Por ello, es parte de la cultura local que las ceremonias vinculadas al Estado nacional se entrecrucen y sincreticen con conmemoraciones que suponen "puramente indígenas".

Devotos de las fiestas patrias, muchos de los que se denominan "calchaquíes" se engalanan para esas oportunidades con vestimentas de gauchos, luciendo con orgullo impecables gruesas ristras de plata, holgados ponchos colorados ribeteados en blanco, redondos sombreros negros de alas anchas, bombachas y guardamontes en sus caballos con arneses de plata. Los mismos se nuclean dentro de Amaicha en "asociaciones gauchas" que compiten por la conservación de la "tradición". Esta, según los casos, puede ser referida explícitamente a lo gaucho, es decir a lo criollo, y por lo tanto a uno de los orígenes míticos de la Argentina.

Esta complejidad del problema es objeto de debate para amaicheños y foráneos dentro de los

18 Que en las Reflexiones finales retomo a través de indagaciones de Toni Morrison. 
Valles. En 1995, por ejemplo, un grupo de los más encumbrados defensores de la "tradición" de la Cédula Real y entonces de la identidad calchaquí propusieron hacer una gran ceremonia de reconocimiento del origen de la Nación Argentina en Amaicha. Ellos la bautizaron "La Primer Argentina", ya que sostenían que el primer territorio en estos perdidos parajes americanos, admitida como "libre" por el rey de España, fue Amaicha del Valle, con una centuria de antelación a la reconocida Independencia de $1816 .{ }^{19}$

Los posicionamientos identitarios de los actores, que para un atento observador implican la mezcla de varias tradiciones, con sus especiales matices y énfasis, para muchos nativos puede simplemente resultar la elección de una de ellas, sosteniendo con vehemencia que la considera y respeta en forma pura. El posicionamiento no es un hecho completamente fortuito, depende de la historia regional y familiar, del imaginario social, de las relaciones sociales que ciñen y nutren al individuo, pero especialmente de la interlocución. O sea, de la situación y del carácter de interlocutor específico ante quien "uno" se posiciona.

En una sociedad compleja como la que trato, las identidades son variadas. Las formas de representar a "lo gaucho" o a "lo indio" dependen de las circunstancias de cada amaicheño. Resultando así un bricolage colorido de usos y costumbres, que continuamente se transforma mezclándose en las prácticas conscientes o no de los actores.

Cuando nos encontramos con situaciones de subordinación la posibilidad de mezcla se acrecienta. Ya Gramsci había pensado esto al caracterizar a la cultura popular o subalterna como un magma en permanente ebullición, compuesto de fragmentos de diversas tradiciones, reelaboradas y resignificadas en un trabajo perpetuo. De allí su definición de sincretismo como:

“...concepción del mundo no sólo no elaborada y asistemática, ya que el pueblo (el conjunto de las clases subalternas...) por definición, no puede

19 La festividad fracasó por falta de fondos, pero hasta el presente numerosos amaicheños hablan con orgullo de constituir la Primer Argentina, con "más derechos que los porteños", compitiendo, paradójicamente desde lo calchaquí, por una nacionalidad que tardó casi dos siglos en darles algún reconocimiento. tener concepciones elaboradas, sistemáticas y políticamente organizadas de los mismos, tanto por su desarrollo contradictorio, como también múltiple; no sólo en el sentido de diverso, y yuxtapuesto... de todas las concepciones del mundo y de la vida, que se han sucedido a lo largo de la historia; la mayor parte de las cuales, se encuentran sólo en el folclore como documentos sobrevivientes mutilados y contaminados" (1971: 268; el subrayado es mío).

Lo que fundamenta la existencia de varias memorias $^{20}$ en una misma colectividad, que pueden no ser radicalmente opuestas, pero que en sus diferentes acentos, sobre por ejemplo idénticos acontecimientos y lugares, generan discursos que disputan el sentido de la historia.

Estas mezclas, contaminaciones y mutilaciones que producen las voces de los actores, enriquecen la cultura popular. En el sentido de que generan un repertorio de respuestas variadas y cambiantes frente a la subordinación. Ser "comunero" de Amaicha o Quilmes implica una identidad sincrética: se mezclan de manera fragmentaria y desordenada textos o narraciones de diferentes tradiciones culturales: especialmente de la criolla, donde "lo indígena" es más que nada una recreación.

\section{Reflexiones finales}

La memoria, como narración del pasado -fragmentos narrativos, a veces separados por hiatos intencionales, por desvanecimientos, por olvidos, en el flujo del recordar-, es un campo de abundantes disputas, cuando se dirimen identidades nacionales o étnicas. Las conmemoraciones colectivas resultan escenarios propicios para que las biografías particulares y la acción de rememorar de los sujetos se inscriban en una memoria oficial, o en proceso de serlo. Esas celebraciones son cronotópicas, pues además de rememorar ensalzando aspectos significativos del pasado para los participantes, intentan determinar el futuro en el presente de las mismas, esculpiendo el devenir en las expresiones simbólicas de los rituales conmemorativos, en la forma de deseos e intenciones sobre la nación o la etnia.

20 Varias memorias, es decir, varias expresiones de la dialéctica entre el recordar y el olvidar. 
La memoria, entonces, como narración del pasado pero que incide en el presente y en el futuro, especialmente cuando intenta contribuir al mismo como emblema político, es un campo de fuerzas, de luchas de poder por inscribir determinados símbolos, y además por el sentido mismo de ellos. De allí que podamos hablar de varias memorias en disputa dentro de un mismo grupo social.

Las narrativas de la memoria, como he tratado de mostrar en este breve artículo, constituyen una arena de disputas en la cual se justifica hablar de políticas del significado, pues se enfatizan determinados acontecimientos muchas veces convirtiéndolos en conmemoraciones, mientras otros son relegados al olvido. En estas narrativas se encuentran impresos las marcas del poder y las jerarquías de género, de clase, de raza, de etnia. He tratado el caso de Amaicha del Valle para ilustrar ciertos aspectos de una emergencia étnica indígena, sin embargo muchos de los enunciados aquí adelantados son posibles de utilizar en sociedades y Estados nacionales como, por ejemplo, el análisis del historiador Patrick García (2001: 3435) sobre la profusión, y su finalidad, de conmemoraciones en la Francia de los tiempos recientes de la presidencia de Valéry Giscard d'Estaing.

Pero fuera de la posibilidad de una memoria consagrada por el poder del Estado, en aquellas memorias que se tratan de construir "contra" aquel poder, o sea, contra o en los costados de la "memoria oficial", el esquematismo puede resultar en el debilitamiento de las relaciones sociales atentando contra la unidad del conjunto. El peligro que acecha a los grupos indígenas e indigenistas en las luchas por sus reivindicaciones históricas, y entonces en la necesidad de construir una narrativa casi siempre mítica del pasado, es el de esclerotizar los acontecimientos, e intentar inmovilizar la historia, simplificándola y empobreciéndola. Si bien el efecto inmediato es la posibilidad de utilización emblemática de su propia historia en relación a las necesidades políticas del presente, uno de los riesgos es que el esquema- tismo contribuya a profundizar clivajes existentes, o coadyuve en la generación de nuevos faccionalismos, debilitando los procesos de identidades emergentes, que se están produciendo en los diferentes culturas indígenas en Argentina desde fines de los ' 80 .

Toni Morrison se ha preguntado por el "sitio" de la memoria después de haber realizado una síntesis admirable de los escritos de los siglos XVIII y XIX de esclavos emancipados de origen africano en los Estados Unidos. Ella concluyó, después de la lectura de decenas de escritos en inglés en forma de cuentos, novelas, poesía (muchos anónimos o con nombres apócrifos) que ese "lugar" fue -y siempre lo será, mientras haya, o resurjan formas de resistencia- lo que llamó "la memoria emocional", definiéndola como lo que recuerdan "los nervios y la piel" (1994: 306).

Esto debería servir para terminar de entender muchas de las conexiones entre "memoria e identidad" en los grupos indígenas de Argentina, los cuales han sufridos pérdidas irreparables; también permite iluminar los múltiples significados de aquello que un líder amaicheño señaló "conservamos el cuerpo, pero perdimos el alma”.

Por fin, creo importante reiterar que la memorización de la Cédula Real, por ejemplo, constituye una "política de identidad" en la medida que permite generar los límites de un "nosotros" como calchaquíes, para la defensa de un territorio, pero además para situarse frente a la identidad que promueve el Estado-nación argentino, con sus conmemoraciones de un pasado donde la indígena en el mejor de los casos es una ausencia, y en el peor, "el salvajismo".

La memoria Calchaquí de la Cédula Real, como la del Estado-nación, están relacionadas a procesos identitarios específicos, y por eso ambas tienes finalidades políticas, pues permiten advertir intencionalidades de hegemonía por medio de una política de la memoria. 


\section{REFERENCIAS CITADAS}

BAJTIN, M., 2003 [1979]. Estética de la creación verbal. Siglo XXI Editores, Buenos Aires.

BENJAMIN, W., 1989. Discursos interrumpidos I. Filosofía del arte y de la historia. Taurus, Buenos Aires.

CARRISO, A., 1937. Cancionero popular de la provincia de Tucumán. Universidad Nacional de Tucumán, Tucumán.

CARTER, W. y X. ALBO, 1988. La comunidad aymara: Un mini Estado en conflicto. En Raíces de América. El mundo aymara. X. Albó (Comp.), pp. 83-107. Alianza Editorial, UNESCO, Madrid.

DETIENNE, M., 1994 [1967]. Les maîtres de vérité dans la Grèce archaïque. Agora, París.

GARCIA, P., 2001. Exercices de mémoire? Les pratiques commémoratives dans la France contemporaine. Cahiers français 303: 33-40.

GRAMSCI, A., 1971. Letteratura e vitta nazionale. Quaderni del carcere. Editori Riuniti, Roma.

HUBERT, H. y M. MAUSS, 1909. Etude sommaire de la représentation du temps dans la religion et la magie. En Mélanges d'histoire des religions, $\mathrm{H}$. Hubert y M. Mauss (Eds.), pp. 83-127. Librairie Felix Alcan, París.

ISLA, A., 1984. Sistemi per l'adattamento socioculturale nelle terre alte a Sud del Lago Titicaca. Studi per l'Ecologia del Quaternario 6: 103-124.

- 1998. Terror, memory and responsibility in Argentina. Critique of Anthropology 18 (2): 134-157.

-2002. Los usos políticos de la identidad. Indigenismo y Estado. Editorial de las Ciencias, Buenos Aires.

LAMBEK, M. y P. ANTZE, 1996. Introduction. Forecasting memory. En Tense past. Cultural essays in trauma and memory, P. Antze y M. Lambek (Eds.), pp. XI-XXXVIII. Routledge, Nueva York, Londres.
LEACH, E., 1966. Two essays concerning the symbolic representation of time. En Rethinking Anthropology, E. Leach (Ed.), pp. 124-143. University of London, Londres.

LIZONDO, E., 1987 Ms. Investigación y estudio de las comunidades en la provincia de Tucumán. La titularidad de Dominio de las Tierras de la Comunidad de Amaicha del Valle, preparado para el diario La Gaceta de Tucumán.

MORRISON, T., 1994. The site of memory. En Out there: Marginalization and contemporary cultures, R. Ferguson, M. Gever, T. T. Minh-ha y C. West (Eds.), pp. 299-305. The Mit Press, Cambridge, Massachusetts.

NORA, P., 1997 [1984]. Entre mémoire et Histoire. La problématique des lieux. En Les lieux de mémoire, P. Nora (Ed.), pp. 25-43. Quarto Gallimard, París.

RAPPAPORT, J., 1987. Mythic images, historical thought and printed texts: The Páez and the written word. Journal of Anthropological Research 43 (1): 43-61.

RICOEUR, P., 1991. Temps et récit. Seuil, París.

RIVIERE, G., 1995. Caminos de los muertos, caminos de los vivos. Las figuras del shamanismo de las comunidades aymaras del altiplano boliviano. Antropología 10: 109-133.

ROUSSO, H., 1991. Pour une histoire de la mémoire collective: L'après-Vichy. Les usages politiques du passé: Histoire et mémoire. En Histoire politique et sciences sociales, D. Peschanski, M. Pollak y H. Rousso (Eds.), pp. 243-265. Editions Complexe, París.

SANCHEZ, S., 1996. Fragmentos de un tiempo largo. Tilcara entre fines del siglo XVI y principios del XIX. Tesis de Licenciatura inédita, Universidad Nacional de Jujuy, San Salvador de Jujuy.

\section{Periódicos}

La Gaceta, San Miguel de Tucumán, 28/07/74. 